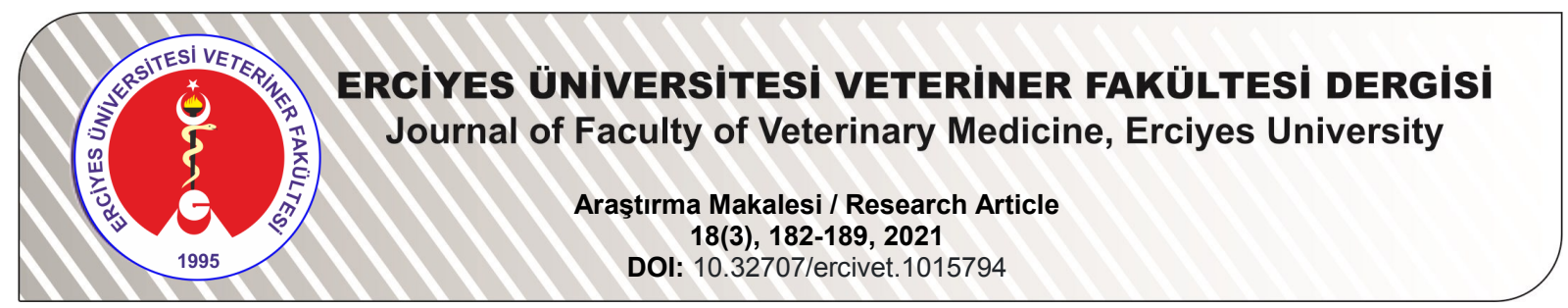

\title{
Erciyes Üniversitesi Veteriner Fakültesi Eğitim, Araştırma ve Uygulama Hastanesi’ne Getirilen
} Hayvanların Uyum Analizi ile Değerlendirilmesi*

\author{
Abdullah ŞiMŞEK ${ }^{1, s}$, Aytaç AKÇAY ${ }^{2, b}$ \\ ${ }^{1}$ Kastamonu Üniversitesi, İhsangazi Meslek Yüksekokulu, Veterinerlik Bölümü, Laborant ve Veteriner Sağlık Programı, \\ Kastamonu-TÜRKIYE \\ ${ }^{2}$ Ankara Üniversitesi, Veteriner Fakültesi Zootekni ve Hayvan Besleme Bölümü Biyoistatistik Anabilim Dalı, Ankara-TÜRKIYE \\ ORCID Numbers; ${ }^{a} 0000-0002-4077-3222 ;{ }^{b} 0000-0001-6263-5181$
}

Sorumlu yazar: Abdullah ŞiMŞEK; E-mail: abdullahsimsek@kastamonu.edu.tr Atıf yapmak için: Şimşek A, Akçay A Erciyes Üniversitesi Veteriner Fakültesi Eğitim, Araştırma ve Uygulama Hastanesi'ne getirilen hayvanların uyum analizi ile değerlendirilmesi. Erciyes Uni Vet Fak Dergisi 2021; 18(3): $182-189$

Öz: Bu çalışmada, Erciyes Üniversitesi Veteriner Fakültesi Eğitim Araştırma ve Uygulama Hastanesine 2013-2016 yılları arasında getirilen 9064 adet hayvan; tür, yaş, cinsiyet, getirildiği bölge, mevsim, geldiği klinik, geliş nedeni ve uygulanan tedavi olmak üzere toplam 8 adet değişken yönünden uyum analizi yöntemi ile incelenmesi amaçlanmıştır. Çalışma bulgularına göre, Erciyes Üniversitesi Veteriner Fakültesi Eğitim Araştırma ve Uygulama Hastanesine 20132016 yılları arasında gelen hastaların sayısı yıllara göre artış göstermiş ve 2016 yılında 4043'e ulaşmıştır. Getirilen hastaların tamamına yakını (\%95.3) Kayseri ilinden olup, \%2.1'i Nevşehir ve \%2.6'sı ise diğer (Kırşehir, Niğde, Kahramanmaraş, Sivas, Yozgat) çevre illerdendir. Hayvan hastanesine getirilen hayvanların yarısından fazlası (\%50.5) iç hastalıkları kliniğine, \%41.2'si ise cerrahi kliniğine getirildiği belirlenmiştir. Uyum analizi sonuçlarına göre; hayvan hastanesi kliniklerine getirilen yaşlı (5 yaş ve üzeri) hayvanlar genellikle genel durum bozukluğu şikâyeti ile genç (1-5 yaş) ve yavru (0-1 yaş) hayvanlar ise aşı yaptııılmak amacı ile kliniklere getirildiği tespit edilmiştir. Ayrıca iç hastalıkları ve cerrahi kliniğine getirilen hayvanların sırasıyla aşı ve operasyon için başvurduğu belirlenmiştir.

Anahtar kelimeler: Erciyes Üniversitesi, hayvan hastanesi, uyum analizi, veteriner

\section{Evaluation of Animals Which are Brought to Erciyes University Veterinary Faculty Training, Research and} Application Hospital Using Correspondence Analysis

Abstract: In this study, 9064 animals brought to Erciyes University Veterinary Faculty Training, Research and Application Hospital between 2013-2016; It is aims to study a total of 8 variables in terms of species, age, gender, region of origin, season, clinic type, the reasons and the treatment applied by through correspondence analysis. According to the results, the number of the patients brought to the Research and Application Hospital of the Veterinary Medicine Faculty of Erciyes University between the years of 2013 and 2016 has increased over the years and reached 4043 in 2016. Almost all of the patients (95.3\%) brought were from Kayseri, 2.1\% from Nevşehir and 2.6\% from other (Kırşehir, Niğde, Kahramanmaraş, Sivas, Yozgat) provinces. It was determined that more than half $(50.5 \%)$ of the animals were brought to the internal medicine clinic and $41.2 \%$ to the surgery clinic. The result of the correspondence analysis revealed that older animals ( 5 years and over) brought to hospital clinics had been brought to the clinics with complaints of general condition disorder, and the young (1-5 years) and newborn(0-1 years) animals had been vaccinated. In addition, it was determined that the animals brought to the internal medicine and surgery clinic for vaccination and operation respectively.

Keywords: Animal hospital, correspondence analysis, Erciyes University, veterinary

\section{Giriş}

Veteriner hekim tüm evcil ve yabani hayvanların hastalıklarının teşhis ve tedavileri, üreme ve ıslahı zoonoz hastalıkların önlenmesi, çiftlik hayvanları, pet hayvanları ve kümes hayvanlarının yetiştirme şartlarının belirlenmesi, verimlerinin artırıması, sağlıklarının korunması, salgın hastalıkların önlenmesi, hayvansal ürünlerin kalitesinin, niteliğinin ve insan sağlığına uygunluğunun denetlenmesi ve hayvan refahı konu-

Geliş Tarihi/Submission Date : 09.03.2021

Kabul Tarihi/Accepted Date : 08.08.2021

*Yüksek Lisans Tezinden Özetlenmiştir. sunda deneyimli meslek sahibi kişilerdir (Özgür, 1997).

Veteriner hekim adaylarının, veteriner fakülteleri arasında tercih yaparken, fakültelerin bulunduğu bölgeye hayvan sağlığı alanında hizmet sunabiliyor olması, öğrencilerin başarısının artırılması ve donanımlı birer hekim olarak mezun olabilmesi için teorik derslerin yanı sıra uygulama imkânı sunan laboratuvarların ve hayvan hastanelerinin bulunması önem arz etmektedir. Hayvan hastaneleri bulundukları bölgede hizmet veren kliniklerden daha geniş donanım ve alt yapıya sahip olmaları, her alanda konunun uzmanı hekimlerden oluşan kadrosu gibi avantajlı yanlarıyla hasta 
sahipleri tarafından gün geçtikçe tercih edilirlikleri artmaktadır. Erciyes Üniversitesi, Veteriner Fakültesi, Eğitim Araştırma ve Uygulama Hastanesi de bölgesine başarılı bir şekilde hizmet veren bu hastanelerden biri niteliğindedir (Anonim, 2019).

Türkiye'de veteriner fakülteleri hayvan hastanelerine getirilen kayıtların incelendiği birçok bölgesel çalışma bulunmaktadır. Bu çalışmaların tamamı bölgesel olarak kısıtlı örneklemde yapılmıştır. Çalışmalardan bazıları sadece bir kliniğe getirilen hayvanları incelemiştir (Pamuk ve ark., 2009; Şimşek, 2008; İşler ve ark., 2015; Yılmaz, 2002).

Uyum Analizi, kategorik olarak sınıflandırılan verilerin yorumlanmasını sağlayan, çapraz tablolardaki değişkenler arasındaki farklılık ya da benzerlik ve ilişkilerini açıklayan, kategorilerin birbiri ile ilgili olan değişimlerini daha az boyutlu bir uzayda şekilsel olarak gösteren bir yöntemdir. Bu yöntem, kategorik veya sınıflandırılmış sürekli değişkenlerin, kategorileri arasındaki farklılıkların ya da benzerliklerin uzaklıklar cinsinden ifade edilmesini; hangi kategorinin diğerlerine göre daha çok benzer olduğunun bulunmasını ve çapraz tablolardaki değişkenlerin birden fazla alt kategorileri arasındaki benzerlikleri daha sade bir biçimde grafiksel olarak görüntülemeyi amaçlar (Suner ve Çelikoğlu, 2008).

Uyum Analizinin kullanım amaçları ise; a- çapraz tablolardaki satır ve sütün kategorileri arasındaki ilişkiyi grafiksel olarak göstermek ve bu gösterimi sağlayacak basit faktörler geliştirerek, eşzamanlı olarak hangi sütun/satır kategorisinin hangi satır/ sütun kategorisi üzerinde daha fazla ağırığa sahip olduğu belirlemek, b- çok değişkenli çapraz tabloların boyut indirgemesi sağlamak, c- bir tablonun taşıdığı bilgiyi taşıyan daha az sayıda ve azalan önem sırasında faktör çıkarmak ve bir ilişki ölçüsü olarak düşünülebilecek olan toplam ki-kare değerinin ayrıştırılmasıdır (Kılıç, 2016).

Bu çalışmada, Erciyes Üniversitesi, Veteriner Fakültesi, Eğitim Araştırma ve Uygulama Hastanesine 2013-2016 yılları arasında getirilen 9064 adet hayvan; tür, yaş, cinsiyet, getirildiği bölge, mevsim, getirildiği klinik, geliş nedeni ve uygulanan tedavi olmak üzere toplam 8 adet değişken yönünden uyum analizi yöntemi ile incelenmesi amaçlanmıştır.

\section{Gereç ve Yöntem}

Çalışma materyalini; 2013-2016 yılları arasında Erciyes Üniversitesi, Veteriner Fakültesi, Eğitim Araştırma ve Uygulama Hastanesi kliniklerine getirilen hastalara ait kayıt bilgileri oluşturmuştur. Kayıtların kullanımı için yetkili kurumlardan gerekli izin alınmış, 2013 -2015 yıllarına ait hasta kayıtları, hasta kayıt defterlerinden temin edilmiş, eksik ve hatalı kayıtlar dışında tüm bilgiler elektronik ortama aktarılmıştır. 2016 yılına ait hasta kayıtları ise hastane kayıt sisteminden seçilerek elektronik olarak temin edilmiştir. Çalışma gerecini oluşturan kayıtlarda toplamda 9064 hastaya ait bilgiler analiz edilmiştir. Hastalara ait kayıtlardan kliniğe gelen hayvanın türü, yaşı, cinsiyeti, getirildiği bölge, mevsim, getirildiği klinik, geliş sebebi ve uygulanan tedavi olmak üzere olarak toplam 8 değişkene ait bilgiler elektronik ortamda kayıt edilerek veri kütüğü oluşturulmuştur. Eksik ve hatalı olan kayıtlar veri girişi sırasında belirlenerek hata payının en düşük seviyede tutulması sağlanmıştır. Çalışma kapsamına alınan değişkenlere ait tanımlayıcı istatistikler yapılarak; değişkenler arası ilişkileri gösteren çapraz tablolar oluşturulmuştur. Ayrıca, değişkenlerin birbirleriyle olan ilişkilerinin iki ya da ikiden fazla boyutlu çapraz tablolarla incelenmesi amacıyla çok değişkenli istatistik analizlerden uyum analizi (Correspondence Analysis) yöntemi kullanılmıştır.

Uyum Analizi, kategorik olarak sınıflandırılan verilerin yorumlanmasını sağlayan, çapraz tablolardaki değişkenler arasındaki farklılık ya da benzerlik ve ilişkilerini açıklayan, kategorilerin birbiri ile ilgili olan değişimlerini daha az boyutlu bir uzayda şekilsel olarak gösteren bir yöntemdir. Bu yöntem, kategorik veya sınıflandırılmış sürekli değişkenlerin, kategorileri arasındaki farklılıkların ya da benzerliklerin uzaklıklar cinsinden ifade edilmesini; hangi kategorinin diğerlerine göre daha çok benzer olduğunun bulunmasını ve çapraz tablolardaki değişkenlerin birden fazla alt kategorileri arasındaki benzerlikleri daha sade bir biçimde grafiksel olarak görüntülemeyi amaçlar (Suner ve Çelikoğlu, 2008).

Uyum analizinde kullanılan verilerin dağılımla ilgili bir varsayımı yoktur. Uyum analizi, özellikle satır ve sütun sayısı fazla olan (kategori sayısı fazla olan) çapraz tabloların çözümlenmesinde tercih edilir (Kılıç, 2016).Uyum analizi elde edilen karmaşık yapıdaki veri dağılımının bir bilgi kaybı yaratmayacak şekilde daha basit (indirgenmiş) yapıda yeni bir veri dağılımı ile ortaya koymaktır. Diğer bir ifadeyle, satır ve sütun değişkenleri arasındaki ilişkiyi daha basit yapıda yeni bir matris ve grafik ile açıklamaktır. Yöntem, kontenjans tablosu ya da iç içe kontenjans tablo biçiminde gösterilen değişkenlerin alt sınıflarındaki yoğunlaşmalarını "Öklid uzaklığı" ya da "Pearson ki kare" uzaklığı cinsinden hesaplayarak ağırlıklı ana bileşenlere göre analiz eder (Vendrik MCM, 2013). Bu çalışmada uzaklıklarım hesaplanmasında "Pearson ki kare" yöntemi kullanılmış ve sonuçların analiz edilmesinde "IBM SPSS Statistics 25" yazılımından faydalanılmıştır. Uyum analizi ki-kare uzaklığı temeline dayanır ve genel formülü şu şekildedir:

$$
X^{2}=\sum \frac{(\text { Gözlenen-Beklenen })^{2}}{\text { Beklenen }}
$$




\section{Bulgular}

Yapılan çalışmada,2013-2016 yılları arasında hastane kayıtlardan alınan değişkenlere ait alt kategoriler belirlenmiştir (Tablo 1).
Ien hayvanlardan oluşturmuştur. Klinik dışı bilimlere gelen hastaların oranı \%4.5 olup bunların çoğunluğu Mikrobiyoloji ve Parazitoloji Anabilim Dallarında numune analizi yapılan hastalardan oluşmuştur (Tablo 4).

Tablo 1. İncelenen değişkenler ve alt kategorileri

\begin{tabular}{ll}
\hline Değişkenler & Alt Kategoriler \\
\hline Yıllar & $2013,2014,2015,2016$ \\
Geldiği Bölge & Kayseri, Nevşehir, Sivas, Diğer \\
Geldiği Klinik & Cerrahi, Iç Hastalıkları, Doğum ve Jinekoloji, Patoloji, Dölerme ve Suni \\
Hayvanın Türü & Tohumlama, diğer \\
Hayvanın Cinsiyeti & Köpek, kedi, at, sığır, koyun/keçi, kanatlı, tavşan, diğer \\
Hayvanın Yaşı & Erkek, dişi \\
Geliş Sebebi & Yavru, genç, yaşlı \\
Teşhis ve Tedavi & Aşı, genel durum bozukluğu, travma, operasyon, nekropsi, doğum, diğer \\
Geldiği Mevsim & Aşı, operasyon, ilaç sağaltımı, analiz ve konsültasyon, genel muayene, \\
\hline
\end{tabular}

Erciyes Üniversitesi Veteriner Fakültesi Eğitim Araştırma ve Uygulama Hastanesi'ne 2013-2016 yılları arasında getirilen hastaların yıllık sayı ve yüzde oranları Tablo 2'de verilmiştir. Çalışmanın yapıldığı 20132016 yıllarına ait dönemde hasta sayısı 2013'den 2016'ya kadar devamlı olarak artış göstermiştir.

Tablo 2. Gelen hastaların yıllara göre dağılımı
Erciyes Üniversitesi, Veteriner Fakültesi, Eğitim Araştırma ve Uygulama Hastanesine getirilen hayvanların türlere göre dağılımı Tablo 5'de verilmiştir. Hastaneye getirilen hayvanların türlere göre dağılımına bakıldığında pet (kedi, köpek) hayvanlarının oranı \%70.5 olduğu görülmüştür (Tablo 5 ). Gelen hastaların geti-

\begin{tabular}{lll}
\hline Yıllar & Sayı(n) & Yüzde (\%) \\
\hline 2013 & 1383 & 15.3 \\
2014 & 1669 & 18.4 \\
2015 & 1969 & 21.7 \\
2016 & 4043 & 44.6 \\
\hline Toplam & $\mathbf{9 0 6 4}$ & $\mathbf{1 0 0 . 0}$ \\
\hline
\end{tabular}

Erciyes Üniversitesi Eğitim Araştırma ve Uygulama Hastanesi'ne getirilen hayvanların getirildiği illere ait hayvan sayısı ve yüzde oranı Tablo 3'de verilmiştir. Hastaneye getirilen hayvanların neredeyse tamamına yakını Kayseri (\%95.3) ilinden olmuştur (Tablo 3). rildiği bölgelere göre türlerin dağılımı incelendiğinde; Kayseri bölgesinden en çok pet hayvanlarının (\% 68.3) diğer bölgelerden ise gelen hayvanların daha çok büyükbaş ve küçükbaş hayvan ağırlıklı olduğu görülmüştür.

Tablo 3. Hayvanların geldiği illere göre dağılımı

\begin{tabular}{lcc}
\hline İller & Sayı(n) & Yüzde (\%) \\
\hline Kayseri & 8639 & 95.3 \\
Nevşehir & 189 & 2.1 \\
Kırşehir & 19 & 0.2 \\
Niğde & 68 & 0.8 \\
Kahramanmaraş & 22 & 0.2 \\
Sivas & 41 & 0.5 \\
Yozgat & 86 & 0.9 \\
\hline
\end{tabular}

Erciyes Üniversitesi Veteriner Fakültesi Eğitim Araştırma ve Uygulama Hastanesine getirilen hayvanların getirildiği kliniklere göre hayvan sayısı ve yüzde oranı Tablo 4'te verilmiştir. Hastaneye getirilen hayvanların yarısından fazlası (\%50.5) iç hastalıkları kliniğine ve yarısına yakın kısmı da (\%41.2) cerrahi kliniğine ge-
Erciyes Üniversitesi, Veteriner Fakültesi, Eğitim Araştırma ve Uygulama Hastanesine getirilen hastaların getirildiği mevsime göre dağılımı Tablo 6'da verilmiştir. Hastaneye gelen hastaların mevsimlere göre dağılımlarının benzer olduğu, sonbahar mevsiminde en çok hayvan geldiği (2713) belirlenmiştir. Kanatı hay- 
Tablo 4. Hayvanların getirildiği kliniklere göre dağılımı

\begin{tabular}{lcc}
\hline Klinikler & Sayı(n) & Yüzde (\%) \\
\hline Cerrahi & 3735 & 41.2 \\
İç Hastalıkları & 4575 & 50.5 \\
Doğum ve Jinekoloji & 145 & 1.6 \\
Patoloji & 190 & 2.1 \\
Dölerme ve Suni Tohumlama & 8 & 0.1 \\
Klinik Bilimler Toplamı & $\mathbf{8 6 5 3}$ & $\mathbf{9 5 . 5}$ \\
Mikrobiyoloji & 61 & 0.7 \\
Parazitoloji & 36 & 0.4 \\
Diğerleri & 314 & 3.5 \\
Klinik Dışı Bilimler Toplamı & $\mathbf{4 1 1}$ & $\mathbf{4 . 5}$ \\
\hline Genel Toplam & $\mathbf{9 0 6 4}$ & $\mathbf{1 0 0 . 0}$ \\
\hline
\end{tabular}

Tablo 5. Gelen hastaların türlere göre dağılımı

\begin{tabular}{ccc}
\hline Türler & Sayı(n) & Yüzde (\%) \\
\hline Köpek & 4143 & 45.7 \\
Kedi & 2245 & 24.8 \\
Sığır & 1455 & 16.1 \\
Kanatlı & 551 & 6.1 \\
Koyun-Keçi & 382 & 4.2 \\
Tavşan & 121 & 1.3 \\
At & 61 & 0.7 \\
Diğerleri & 106 & 1.2 \\
\hline Toplam & $\mathbf{9 0 6 4}$ & $\mathbf{1 0 0 . 0}$ \\
\hline
\end{tabular}

Tablo 6. Gelen hastaların mevsime göre dağılımı

\begin{tabular}{ccc}
\hline Mevsim & Sayı(n) & Yüzde (\%) \\
\hline Kış & 1144 & 22.8 \\
İlkbahar & 1114 & 22.2 \\
Yaz & 1386 & 27.6 \\
Sonbahar & 1377 & 27.4 \\
\hline Toplam & $\mathbf{5 0 2 1}$ & $\mathbf{1 0 0 . 0}$ \\
\hline
\end{tabular}

Tablo 7. Gelen hastaların geliş sebebine göre dağılımı

\begin{tabular}{ccc}
\hline Geliş Sebebi & Sayı(n) & Yüzde (\%) \\
\hline Aşı & 2465 & 27.2 \\
Genel Durum Bozukluğu & 4846 & 53.5 \\
Travma & 1363 & 15.0 \\
Operasyon & 55 & 0.6 \\
Nekropsi & 190 & 2.1 \\
Doğum & 145 & 1.6 \\
\hline Toplam & $\mathbf{9 0 6 4}$ & $\mathbf{1 0 0 . 0}$ \\
\hline
\end{tabular}

vanlar hariç, diğer türlerde gelen hastaların \% 50.5 'inin İç Hastalıkları kliniğine geldiği ve bunların da \%15'i Sonbahar aylarında getirildiği görülmüştür.

Erciyes Üniversitesi, Veteriner Fakültesi, Eğitim, Araştırma ve Uygulama Hastanesine getirilen hayvanların geliş nedenlerine göre dağılımı Tablo 7'de verilmiştir. Hastaneye getirilen hayvanların \%53.5'i genel durum bozukluğu şikâyeti ile getirilmiştir.

Erciyes Üniversitesi, Veteriner Fakültesi, Eğitim Araş- tırma ve Uygulama Hastanesine getirilen hayvanların tedavilerine göre dağılımı Tablo 8'de verilmiştir. Hastaneye getirilen hayvanların \%27'si aşı yaptırılmak üzere getirilmiştir. Kliniklere gelen hayvanların en yüksek oranda köpek (\%45.7) ve bunlarında en yüksek oranda aşı (\%14) için geldiği belirlenmiştir. Hayvanların \%30'unun tedavisi ilaç sağaltımı yolu ile gerçekleştirilmiştir. Hastaneye getirilen hayvanların \% 18.7'ne operasyon yapıldığı belirlenmiştir (Tablo 8). 


\section{Uyum analizi bulguları}

Çalışma kapsamına alınan değişkenlerin birbirleri ile olan ilişkilerin basit ve çoklu uyum analizi incelenmiştir. Basit uyum analizi kapsamında; "Geliş sebebiHayvanın yaşı", "Klinik- Hayvanın türü”; çoklu uyum

Tablo 8. Gelen hastaların tedaviye göre dağılımı

\begin{tabular}{ccc}
\hline Tedavi & Sayı(n) & Yüzde (\%) \\
\hline Aşı & 2465 & 27.2 \\
Operasyon & 1696 & 18.7 \\
İlaçla sağaltımı & 2710 & 29.9 \\
Analiz ve Konsültasyon & 411 & 4.5 \\
Genel muayene & 1486 & 16.4 \\
Ölen hayvan & 100 & 1.1 \\
Nekropsi & 190 & 2.1 \\
Tedaviyi ret eden & 6 & 0.1 \\
\hline Toplam & $\mathbf{9 0 6 4}$ & $\mathbf{1 0 0 . 0}$ \\
\hline
\end{tabular}

analizi kapsamında; "Hayvanın cinsiyeti- Geliş sebebi - Hayvanın yaşı","Geliş sebebi-Mevsim- Hayvanın yaşı" ve "Klinik- Mevsim - Hayvanın yaşı" değişkenleri arasındaki ilişkiler incelenmiştir. "Geliş sebebi- Hayvanın yaşı" değişkenlerinin Uyum Analizi sonuçlarının kategorilerin düzlemde gösterimi Şekil 1'de verilmiştir. Şekilde yaşlı hayvanların genel durum bozukluğu nedeni ile getirildiği, yavru hayvanların aşı ve travma yaralanmaları sonucu kliniğe getirildiği söylenebilir. Ayrıca genç hayvanların ağırlıklı olarak travma nedeni ile geldiği değerlendirilmesi de yapılabilir (Şekil 1).

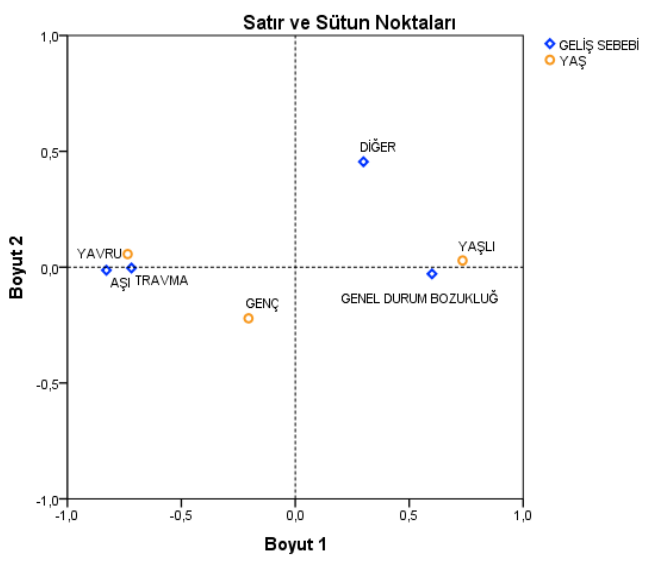

Şekil 1."Geliş sebebi- Hayvanın yaşı" değişkenlerinin birlikte düzlemde gösterimi.

"Klinik-Hayvan türü" değişkenlerinin Uyum Analizi sonuçlarının kategorilerin düzlemde gösterimi Şekil 2'de verilmiştir. Şekilde cerrahi kliniğine büyükbaş hayvan daha fazla geldiği, İç Hastalıkları kliniğine pet hayvanları (kedi-köpek) geldiği söylenebilir. Ayrıca diğer bölümlere farklı türlerden hastaların geldiği söylenebilir (Şekil 2).

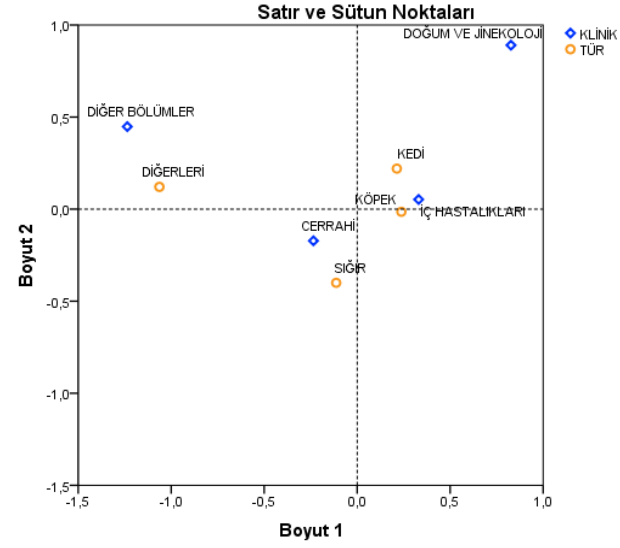

Şekil 2."Klinik- Hayvan türü” değişkenlerinin birlikte düzlemde gösterimi.

"Hayvanın cinsiyeti- Geliş sebebi- Hayvanın yaşı" değişkenlerinin çoklu uyum analizi sonuçlarına göre cinsiyet değişkeninde erkek hayvanların dağılımı fazla olduğu, yaş değişkeninde yaşlı hayvanların ve geliş sebebi değişkeninde genel durum bozukluğunun dağılımı yüksek oranda tespit edilmiştir. Ayrıca nokta koordinatları incelendiğinde genç ve yavru yaştaki hayvanların orijine yakın olduğu geliş sebebine göre diğer nedenlerin ise orijine en uzak noktada konumlandığı belirlenmiştir. Çoklu Uyum Analizi sonuçlarının kategorilerin düzlemde gösterimi Şekil 3'da verilmiştir. Şekilde yavru ve genç hayvanların aşı için kliniğe geldiği, yaşlı hayvanların genel durum bozukluğu nedeni ile geldiği, ayrıca erkek hayvanların genelde travma, dişi hayvanların diğer nedenler ile getirildiği yorumu yapılabilir (Şekil 3). 


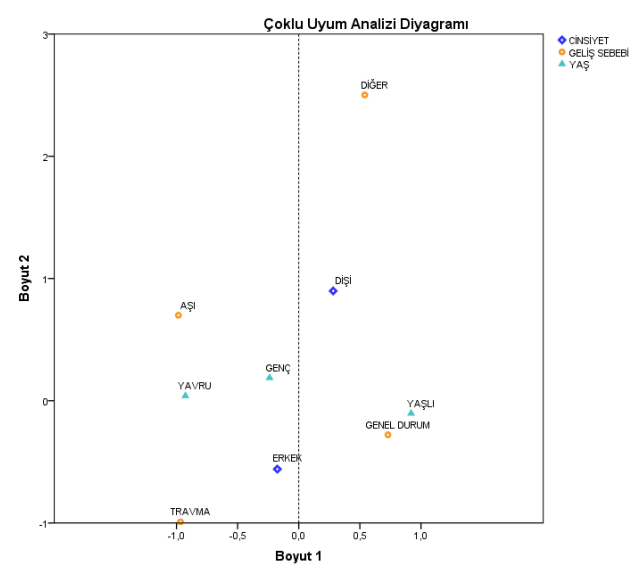

Şekil 3."Hayvanın cinsiyeti- Geliş sebebi- Hayvanın yaşı", değişkenlerinin birlikte düzlemde gösterimi.

"Geliş sebebi- Mevsim- Hayvanın yaşı" değişkenlerinin çoklu uyum analizi sonuçlarına göre yaş değişkeninde yaşlı hayvanların dağılımı fazla olduğu, geliş sebebi değişkeninde genel durum bozukluğunun dağılımı yüksek oranda tespit edilmiştir. Ayrıca nokta koordinatları incelendiğinde genç ve yavru yaştaki hayvanların orjine yakın olduğu geliş sebebine göre diğer nedenlerin ise orjine en uzak noktada konumlandığı belirlenmiştir. Çoklu Uyum Analizi sonuçlarının kategorilerin düzlemde gösterimi Şekil 4'de verilmiştir. Şekle göre yaz aylarında genç hayvanların aşı için getirildiği, sonbahar mevsiminde genel durum bozukluğu nedeni ile geldiği tespit edilmiştir. Ayrıca yavru yaştaki hayvanların kış aylarında travma nedeni ile geldiği değerlendirilmesi yapılabilir (Şekil 4).

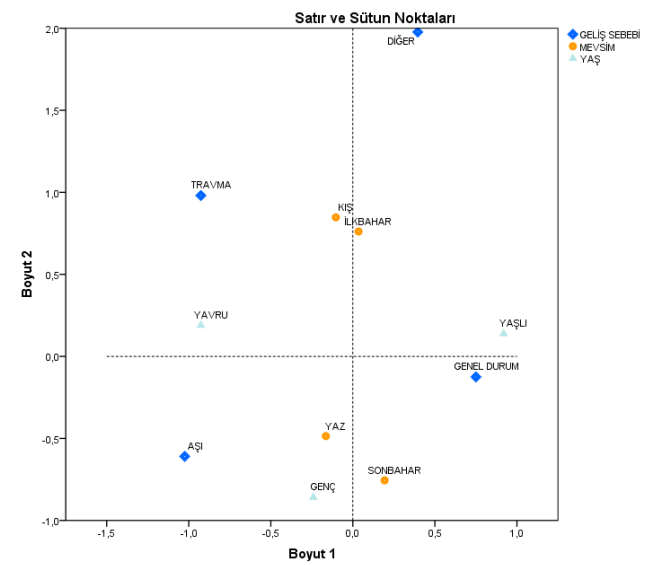

Şekil 4."Geliş sebebi- Mevsim- Hayvanın yaşı" değişkenlerinin birlikte düzlemde gösterimi.
"Klinik- Mevsim - Hayvanın yaşı" değişkenlerinin çoklu uyum analizi sonuçlarına göre yaş değişkeninde yaşlı hayvanların, mevsim değişkeninde ve klinik değişkeninde İç hastalıkları kliniğinin dağılımı yüksek oranda tespit edilmiştir. Ayrıca nokta koordinatları incelendiğinde genç ve yavru yaştaki hayvanların orijine yakın olduğu, diğer kiniklere gelen hastaların ise orijine en uzak noktada konumlandığı belirlenmiştir. Çoklu uyum analizi sonuçlarının kategorilerin düzlemde gösterimi Şekil 5'te verilmiştir. Şekilde yaz aylarında yavru hayvanların cerrahi kliniğine getirildiği, sonbahar ve kış mevsimlerinde genç hayvanların İç Hastalıkları kliniğine geldiği, yaşı hayvanların diğer bölümlere geldiği değerlendirilmesi yapılabilir (Şekil $5)$.

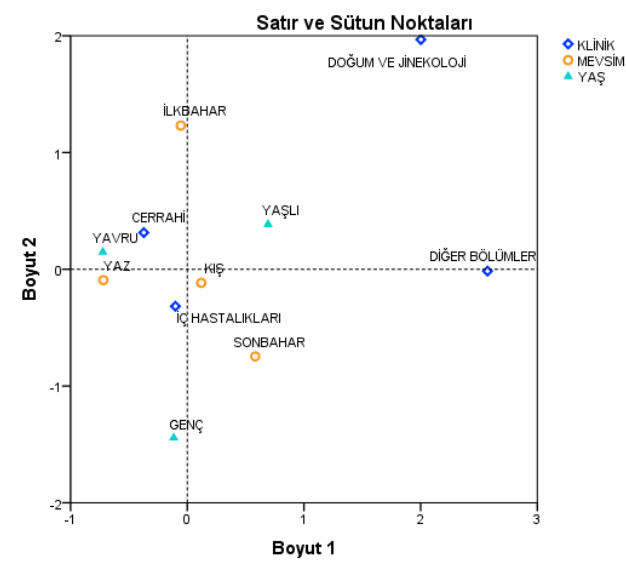

Şekil 5. "Klinik- Mevsim - Hayvanın yaşı" değişkenlerinin birlikte düzlemde gösterimi.

\section{Tartışma ve Sonuç}

Bu çalışmada Kayseri ili ve çevre illerden Erciyes Üniversitesi Veteriner Fakültesi Eğitim Araştırma ve Uygulama Hastanesine getirilen hastaların 20132016 yılları arasındaki dağılımları çeşitli faktörlere göre incelenmiştir. Hastanenin kuruluş sürecinde alt yapı ve reklam yetersizlikleri neden ile gelen hasta sayıları sınırlı düzeyde kalmıştır. Günümüzde tüm alt yapıları tamamlanmış ve $7 / 24$ hizmet vermeye başlayan hastanede hasta sayısı giderek artarak 2016 yılında 4000'in üzerine çıkmıştır. İlk yıllarda kayıtların kayıt defteri kullanılarak elle eksik ve hatalı bilgilerin sayısında artışa neden olurken, 2016 yılından itibaren otomasyon sistemine geçen hastanede kayıtlarda hata miktarı minimum düzeye indirilmiştir. Erciyes Üniversitesi, Veteriner Fakültesi, Eğitim, Araştırma ve Uygulama Hastanesine 2013-2016 yılları arasında gelen hastaların \%44.6'sı 2016 yılında getirilmiştir. illere göre kıyaslama yapıldığında hastaların büyük bir kısmının (\%95.3)'ü Kayseri'den gelen hastalar olduğu, \%2.1'inin Nevşehir'den getirildiği tespit edilmiştir. Kliniklere göre dağılımında \% 50.5'ini iç hasta- 
lıkları, \%41.2'sini cerrahi oluşturmuştur. Gelen hayvanlar tür bazında değerlendirildiğinde \%45.7'si köpek, \%24.8'i kedi ve sadece \%16.1'i büyükbaş hayvanlar oluşturmaktadır. Gelen hastaların \%39.8'i yavru (0-1 yaş) aralığındaki hayvanlardan oluştuğu belirlenmiştir. Gelen hastaların \% 53.5'i genel durum bozukluğu şikâyeti ile hastaneye başvururken \%27.2'si aşı yaptırmak amacı ile gelmiştir. Gelen hastaların \% 29.9'u ilaçla sağaltım yapıımıştır. Operasyon oranı \% 18.7 olarak belirlenmiştir. Bu çalışmada Cerrahi kliniğine getirilen hayvanların büyük çoğunluğu kedi ve köpek olduğu tespit edilmiştir. Bunun nedeni hastanenin henüz alt yapı çalışmalarının 2016 yılına kadar tam olarak sağlanamadığı, büyükbaş hayvanların genellikle kırsal alanda yetiştirildiği ve nakliye olanaklarının kısıtılığı ve serbest veteriner hekimlerin bu alandaki yeterliliğinden kaynaklanmış olabilir. Ancak Pamuk ve ark. (2009) tarafından yılında yapmış çaIışmada Afyon Kocatepe Üniversitesi, Veteriner Fakültesi, Cerrahi kliniğine getirilen hayvanların dağılımı incelenmiş ve getirilen hayvanların büyük çoğunluğunu büyükbaş hayvanların (sığır) oluşturduğu görülmüştür.

Mevcut çalışmada iç hastalıkları kliniğine getirilen hayvanların büyük çoğunluğu aşı getirildiği tespit edilirken, Şimşek (2008) tarafından yapılan çalışmada Dicle Üniversitesi, Veteriner Fakültesinde yapmış olduğu çalışmada iç hastalıkları kliniğine getirilen hayvanların büyük çoğunluğunun sindirim sistemi şikâyeti ile kliniğe geldiği belirtilmiştir.

Mevcut çalışmada gelen hayvanların büyük çoğunluğu kedi köpek olmuş ve bunların çoğunluğu opere edilmiş ve bir kısmına da ilaç sağaltımı uygulanmıştır. İşler ve ark. (2015)' nın Mustafa Kemal Üniversitesi, Veteriner Fakültesinde yapmış oldukları çalışmada beş yılda toplam 1293 olgunun; yarısından fazlası pet hayvanları, geri kalan kısmın ise büyük çoğunluğunu çiftlik hayvanları ve kanatlı hayvanlar oluşturmuştur. İşler ve ark. (2015) mevcut çalışmaya benzer şekilde hastaların çoğuna medikal ve bir kısmına da operatif sağaltım uygulamaları için getirildiğini bildirmiştir.

Mevcut çalışmada iç hastalıkları kliniğine 4575 hasta gelmiş ve gelen hastaların 2240 köpek (\%45.7), 1236 kediden (\%24.8) oluşmuştur. Gelen hastaların 1873 tanesi 0-6 ay aralığındaki hastalardan oluşmuştur. Cinsiyete göre dağılımları incelendiğinde yarıdan fazlası erkek hayvanlardan oluşmuştur. Yılmaz (2002), tarafından yapılan çalışmada Uludağ Üniversitesi Veteriner Fakültesi, İç Hastalıkları kliniğine getirilen kedi ve köpeklerin değerlendirilmesi isimli çalışmada 1990-2000 yılları arasında 9297 hasta kayıt altına alınmış ve mevcut çalışmaya benzer şekilde çoğunluğunu 7831'i ile köpek türü oluşturmuştur. Genel yaş ortalaması 0-6 ay aralığında ve cinsiyete göre dağılımları eşit düzeyde tespit edilmiş. Başvuru nedenleri büyük oranda sindirim problemi olarak tespit edilmiştir (Yılmaz, 2002).
Çalışma kapsamında yapılan uyum analizlerinde elde edilen sonuçların grafikle gösterimi yorumların daha kolay yapılmasını ve her bir değişkene ait kategoriler arasındaki ilişkilerin daha anlaşılır olmasını sağlamaktadır. Her bir noktanın orijinden uzaklığı o noktanın yani kategorinin önemini ifade etmektedir. Bu çalışmada yapılan uyum analizlerinde iki boyutlu bir kontenjans tablosundan yararlanarak, her satır ve sütunu bir nokta olarak iki boyutlu düzlemde gösterimi sağlanmıştır. Böylelikle uyum analizi, çok karmaşık tabloların grafikler yardımıyla kolay bir şekilde yorumlanması kolaylığını sağlamıştır. Ayrıca çalışmada uygulamalarda sıklıkla kullanılan iki boyutlu düzlemde noktaların pozisyonlarına göre nasıl yorumlanacağı açıklanmış olup, bundan sonra uyum analizi kullanılarak yapılacak olan uygulamaya yönelik çalışmalara örnek teşkil etmesi hedeflenmiştir.

\section{Teşekkür}

Çalışmanın yapılmasında sağladıkları katkılardan dolayı Erciyes Üniversitesi, Veteriner Fakültesi Dekanlığı ve Eğitim Araştırma ve Uygulama Hastanesi Başhekimliği 'ne teşekkür ederiz.

\section{Kaynaklar}

Alpar R, Dolgun A. Uyum Analizi. Çok değişkenli istatistiksel yöntemler. Üçüncü Baskı. Ankara: Detay Yayınevi 2011; ss. 355-403.

Anonim, Erciyes Üniversitesi Veteriner Fakültesi Eğitim Araştırma ve Uygulama Hastanesi. https:// hayvanhast.erciyes.edu.tr/; Erişim Tarihi:10.05.2019.

Greenacre M, Blasius J. Correspondence Analysis in the Social Sciences. First Edition. USA: Academic Press, 1994.

İşler CT, Altuğ ME, Gönenci R, Yurtal Z. Mustafa Kemal Üniversitesi Veteriner Fakültesi Cerrahi Kliniği'ne getirilen olguların değerlendirilmesi. FÜ Sağ Bil Vet Derg 2015; 29(2): 97-102.

Kılıç AF, Uyum Analizi (Correspondence Analysis). YBS Ansiklopedi 2016; 3(1): 1-20.

Özgür A, Veteriner hekim terimi üzerine tarihsel bir araştırma. Ankara Üniv Vet Fak Derg 1997; 44: 18.

Pamuk K, Sarıtaş KZ, Demirkan I, Korkmaz M. Afyon Kocatepe Üniversitesi Veteriner Fakültesi Cerrahi Kliniğine getirilen hastaların değerlendirilmesi. Kocatepe Vet Derg 2009; 2(1): 29-33.

Suner A, Çelikoğlu CC. Uygunluk analizinin benzer çok değişkenli analiz yöntemleri ile karşılaştırılması. İstatistikçiler Dergisi 2008; 1(1): 9-15.

Şimşek A, Dicle Üniversitesi Veteriner Fakültesinde 
İç Hastalıkları Anabilim Dalı Kliniğine mayıs 2003aralık 2008 tarihleri arasında muayene ve tedavi için getirilen hayvanların genel analizi. Dicle Üniv Vet Fak Derg 2008; 1(2): 25-47.

Maarten MCM. Adaptation, anticipation and social interaction in happiness: An integrated errorcorrection approach, J Public Econ 2013; 105: 131-49.

Yılmaz Z, Uludağ Üniversitesi Veteriner Fakültesi İç Hastalıkları Küçük Hayvan Kliniğine getirilen kedi ve köpeklerin değerlendirilmesi. Uludağ Univ J Fac Vet Med 2002; 21(1): 23-31. 